\title{
The Empathic Ward: Reality and Resistance in Mental Health Reform
}

\author{
Leighton C. Whitaker, PhD, ABPP \\ Private Practice, Media, Pennsylvania \\ Arthur J. Deikman, MD \\ University of California, San Francisco
}

\begin{abstract}
This article provides perspective on our experiment to change a psychiatric hospital ward from reliance on drug therapy to psychological treatment. Resistances to the change took many forms, including delaying publication of the results for nearly a decade. Although successful, the treatment program itself was never adopted. The work did have a major impact on the "right to refuse treatment" case originally titled Rogers v. Okin (1979), which barred forced medication and involuntary seclusion except in certain emergencies if an outside consultant agreed. Two publications (Deikman \& Whitaker, 1979; Whitaker \& Deikman, 1980) described much of the program and its vicissitudes but did not include some of the more resisted features reported in this article.
\end{abstract}

Keywords: psychiatric ward; mental health reform; milieu therapy; severe mental disorder

7 he purpose of this article is to provide perspective on our previous successful experiment to change a psychiatric hospital ward from the practice of relying on

$\int$ drug therapy to relying on psychological treatment. Although achieving our goal of improving treatment outcomes for severe mentally disturbed persons, we encountered severe resistance to accepting our reports as valid. The resistance took many forms, but one result was that we were not able to publish our observations and results for nearly a decade (Deikman \& Whitaker, 1979; Whitaker \& Deikman, 1980).

Our findings aroused an antagonism for which we were not prepared. For example, when we submitted the first article to a major psychiatric journal, two of six reviewers refused even to read our manuscript. The reviewers believed that not using drug treatment for such patients was unacceptable, perhaps even malpractice. Eventually, we circulated our unpublished manuscripts to a few colleagues, one of whom, Michigan State University professor, Bertram Karon, suggested submitting the manuscript to a psychology journal, which we did. The result was that the articles were finally published in Psychotherapy: Theory, Research and Practice, an American Psychological Association Journal.

However, the manuscripts did strike a chord with some professionals. As a result, even before publication, Dr. Whitaker was asked to be a consultant to a VA hospital, to be an expert witness in the "right to refuse treatment case" in Boston's U.S. District Court, to propose a new Massachusetts state mental health plan, and to become superintendent of a 
state hospital. Publication of our two articles brought about 400 reprint requests, including many from foreign countries.

But the treatment program itself has never been adopted. Nor did it appear to have any effect on the tidal wave of drug treatment that has taken place in the United States and throughout the industrialized world, despite evidence of drug induced damage on the one hand and superior results for interpersonal forms of caring on the other. There has been one hopeful development: The right to refuse treatment case, originally titled Rogers v. Okin (1979) set a precedent to disallow forced medication or involuntary seclusion except in certain emergencies and then only if an independent outside consultant agreed.

In the present article, besides reviewing our ward program efforts, the nature of the helping processes, and how staff and patients alike were challenged, we try to explain how the more serious personal and institutional resistances can be understood. Along the way, we shall disclose material we felt unable to publish earlier, including more of the evolution of power and responsibility sharing with the patients. We start by relating how we came to think of operating such a program. We anticipated resistance, but we did not know just what kind of resistance would emerge.

\section{BEFORE THE WARD}

Dr. Whitaker had been serving one of the several psychiatric wards and supervising other psychologists working in the hospital and in the outpatient clinic. Dr. Deikman had been pursuing his career-long, grant-funded research on meditation and states of consciousness. They were both aware that, in sharp contrast to the outpatient clinic's psychoanalytic orientation and ample provision of psychotherapy, the psychiatric hospital relied heavily on drug treatment, with little attention to developing individual or group therapy or the psychosocial aspects of the milieu. Whitaker had written a critique of the psychiatric hospital's treatment program for the sake of his own understanding, assuming it would be of no serious interest to others. But a new hospital director was appointed and he did show interest; he responded by having Whitaker join him in teaching a seminar for the hospital's psychiatric residents, as well as co-lead a group therapy seminar with a staff psychiatrist. Meanwhile, Deikman was planning to take a year off from his research to serve as a psychiatric ward chief. In discussing their professional interests, Whitaker talked particularly of how effective certain forms of group therapy could be, and Deikman talked of how the ideas of psychiatrist K. Artiss (1959) could be applied to milieu therapy. Whitaker and Deikman began to visualize creating a model of treatment integrating group, milieu, and individual therapy, with the goal of making the patients stronger than they were before they became hospitalized.

Whitaker had also been doing research to develop a test of schizophrenic thinking, seeking to determine specifically how people's thinking broke down into the looseness, slowness, and lack of reflective awareness that seemed to define their disabilities, eventually resulting in the Whitaker Index of Schizophrenic Thinking (WIST; 1973, 1980, 1985) and a book (Whitaker, 1992) that rejected the standard but unproven, fatalistic claim of "once a schizophrenic, always a schizophrenic." Whitaker regarded the term "schizophrenia" as a useful working construct only, and not some sort of entity, an "it" or object needing somatic eradication or at least dampening. Such reification of the construct into a presumed entity, a kind of sacred icon, leads to pseudoscience rather than genuine science. 
We felt that inadequate and harmful interpersonal environments were the principal causes of the disabilities called "schizophrenic disorders" and "psychotic depressions," and that positive interpersonal influences could be powerfully therapeutic. But the question remained: might psychotropic medication be helpful also, perhaps adjunctively, in combination with the psychological help? And would we be subject to malpractice charges if we did not employ the recommended standard treatment, that is drugs, especially if either self-inflicted or other-directed violence occurred?

Deikman asked Whitaker, who had already been looking into the effects of drug treatment in his own research project, to do a review and critique of the neuroleptic medication research literature, since antipsychotic drugs such as Thorazine were assumed to be helpful, even if not curative. Whitaker's research using the WIST was already suggesting that the neuroleptics, while making most schizophrenics subdued and unresponsive emotionally, had little or no positive effect on the kind of adaptive thinking ability that is essential to functioning well and productively in the world. Whitaker had not yet realized that while the research literature showed little evidence of drug-produced positive effects on thinking disturbance, there was already ample evidence of damage to bodily systems, not only to the central nervous system, as was especially apparent, for example, in Parkinson-like symptoms such as tremor and shuffling gait, but also a host of other adverse somatic effects. He concluded that while the neuroleptic drug research was severely flawed in terms of substantiating the nearly universal claims of therapeutic benefit, it did clearly substantiate widespread damaging effects.

In further pursuit of assessing the effects of the neuroleptics, Deikman decided to experience the effects of Thorazine firsthand; Deikman actually gave himself a dose one morning and later observed that it was like going around all day covered over by a heavy shag rug. The effect was more dysfunctional and unpleasant than was suggested by the pleasant sounding major tranquilizer label put on the neuroleptics. It did not seem unreasonable that psychological treatment could be superior to forcing a rug over human beings' natural liveliness. In fact, Deikman considered the widespread use of neuroleptic drugs, such as Thorazine, to reflect therapists' unconscious fears keeping them from empathizing and identifying with their emotionally disturbed patients. If nothing else, prescribing pills carried the message: "You're sick-unlike me who doesn't need to take them" (Deikman, 1971). In view of the apparent dearth of truly helpful effects of the phenothiazines, they seemed to be a case of the "emperor's new clothes."

With these factors in mind, Deikman established a policy that neither neuroleptic nor other psychiatric drugs would be prescribed for patients on the ward unless psychological approaches had been tried and found to be insufficient; patients already taking prescribed drugs would be weaned off of them. This new policy clashed with the hospital's standard practice in the psychiatric emergency room. There, psychiatric patients were automatically given powerful neuroleptic drugs at the time of admission. Because of this policy there was seldom opportunity for observation of drug-free behavior.

Thus, we rejected the assumption that schizophrenia and psychotic depression were biochemically based disease entities requiring medical treatment in the form of drugs. We chose not to regard our patients as needing to be patient, passive, and compliant to the staff. Rather, we endeavored to get them emotionally engaged. The degree of quietness on the ward ceased to be a measure of staff competence; instead, successful treatment was expected to result in noise, upsets of various kinds, and challenges to the staff. Our activity was focused on helping patients develop the interpersonal abilities and strengths 
needed to live adaptively-meaning actively and constructively-outside of the hospital. Becoming able to negotiate the social dynamics of the ward-including both patients and staff-was crucial to that goal. Yet the nurses and aides were traditionally taught and graded on the absence of trouble or conflict.

Initially, we had considerable turnover at the head nurse position before we found someone suitable to the milieu and treatment philosophy we were developing. Staff on the other hospital wards were frightened by the news of the no drug policy of our ward. They interpreted that to mean that they might have drugs taken away from them and they had not been taught any other strategies except the use of the seclusion room or restraints. This fear of being left helpless to deal with their patients led them to shun our nurses, to ostracize them, and to refuse to eat with them in the dining hall.

\section{WARD TRUST BUILDING AND POWER SHARING}

In our previous articles (Deikman \& Whitaker, 1979; Whitaker \& Deikman, 1980), we described many of the challenges to staff and patients alike during the 11 months of full operation of the ward. Now, we will relate some examples of trust building and power sharing that, for political reasons, we felt unable to publish previously because they seemed too radical. As described in our previous articles, patient-personnel meetings of the entire ward were characterized increasingly by active patient initiatives to the point that patients began to run some of the meetings. Occasionally, they chose to reverse patient and staff roles and a kind of ironic humor emerged when patients mimicked staff with consequent laughter all around; the patients came to sober realizations as they came to appreciate the difficult challenges of being staff. They concluded that they preferred their easier roles as patients. These temporary role reversals engendered considerable empathy, staff for patients and patients for staff, with a consequent sense of mutual responsibility for one another. What we did not report in our previous articles were the more extreme instances of this growing dynamic.

In October, about 11 weeks into the full operation of the ward, the patients decided to hold a Halloween party for patients and staff, but did not reveal the particulars until the party was underway. It turned out that what the patients had planned was a Salem witch trial during which each staff member was accused of a therapeutic crime and sentenced to have a hand or foot immersed in ice water for a length of time appropriate to the gravity of their misdeed. Every staff member was accused, convicted, and sentenced for their crimes. For example, with suitable irony, Deikman was accused and convicted of prescribing too many drugs.

Next came a more radical request: the patients wanted the keys to the padded, soundproofed isolation room, into which they would herd and seclude all of the staff, and then retain the keys for an unspecified period of time. There was remarkably little hesitation by staff or patients, although patients were nervous about the implicit responsibility, and staff knew it would have been impossible for them to be heard crying out to other hospital personnel for help; some staff were concerned they might become the laughing stock if the patients did not unlock the door and release us. After about 20 minutes of being crowded together in the isolation room, the patients let the staff out for good behavior. (The isolation room, literally a padded cell, was never used, before or after Halloween, 
for involuntary patient isolation; any patient who wished to use it for the sake of peace and quiet was allowed to, but none ever did.)

After the Halloween party, the sense of being a family became much stronger and there was a request by the nurses-voiced at a joint meeting of patients and staff-that the ward be unlocked. Deikman at first turned down the proposal fearing that new patients might elope before they had a chance to respond to the family atmosphere. The nurses told him that he could keep the doors locked, but he could then run the ward by himself because they would leave-they were tired of running back and forth to open and lock the door. Deikman yielded to this very persuasive argument. It was interesting that the patents, as well as the staff, wanted the door unlocked-except for a few patients who had previously wanted to run away! So the door to the ward was unlocked permanently.

However, since the open door would require more staff time than was available it was necessary to discuss how the patient group might help out. It was decided that when new patients, deemed elopement risks, arrived on the ward, some of the patients would monitor them and encourage their participation. This initial involvement in the treatment process became even more prominent when psychodrama sessions were instituted to help patients confront early trauma. For example, the patient group might learn that a particular patient had great trouble becoming conscious of anger and would retreat into delusion. The patient would be confronted by other patients when the issue seemed to manifest itself, for example "You are really very angry now, aren't you? Let it out!" Delusions were seen as defenses, rather than dismissed as craziness. Such confrontations by other patients were very frequent and regarded as a responsibility. One patient even complained that the group did not wake her up at night when they worked with another patient.

The feeling of being a family had been growing on the ward and there was much humor evident. In December the patients wanted an evening party featuring Santa Claus. Again, they insisted upon particulars that deprived staff of any remaining professional distance. They chose to have Whitaker made up as Santa Claus; he would thus sit in a chair costumed for his role, ready to hear the wishes of patients and staff. An otherwise psychotically depressed, hallucinating young woman who had been severely suicidal, appointed herself to apply his makeup, which she did with cheerful enthusiasm and skill. Then every staff member and patient each took a turn on Santa's lap, telling him what they wanted for the coming holidays.

\section{STAFF FEELINGS}

In the process of changing over from reliance on drugs to reliance on psychological treatment, strong staff feelings were aroused. In patient-staff meetings, group psychotherapy, and the overall culture of the ward milieu, staff were challenged to consider their own feelings, as well as the patients' feelings. Instead of restricting themselves to the kind of distancing that is typically considered integral to professionalism, staff were emotionally interactive with patients in ways that tested staff's sensibilities. It became clear that staff emotions could neither be avoided nor dismissed as entirely due to patients' behavior. Individual staff had idiosyncratic emotional reactions that had to be taken into account. In psychoanalytic terminology, staff not only experienced patient transferences to them, but their own countertransference reactions. The latter were considered not to be unfortunate 
feelings about patients, but potentially valuable resources for understanding treatment dynamics, just as in psychodynamic psychotherapy. As Stanton and Schwartz (1954) pointed out in their study of mental hospitals, patient "acting out" is often an expression of staff conflict.

Staff "feelings meetings" were held during some evenings; any staff person could call one at any time it was judged necessary. At such meetings, everyone was encouraged to talk about their own feelings, with the understanding that they were not being judged. One result was that staff, the present writers included, could express their otherwise pent-up frustrations, for example over the fact that there were and would continue to be disruptions to whatever treatment goal or harmony on the ward we were pursuing. We could then sense the commonality of such frustration and the unrealistic wish that we could overcome conflict once and for all, mirroring the inevitable, never fully resolved quality of life itself. Thus, we did not have to conclude individually or collectively that we were not providing good treatment.

\section{THE QUESTION OF VIOLENCE AGAINST OTHERS OR ONESELF}

Patients' other-directed and self-directed violence aroused the greatest concern. Standard practice was to limit the patient by means of drug treatment or isolation. A patient who was already acting out by assaulting others would have to be physically restrained. In one instance on another ward, six male staff tried to contain a young man who appeared out of control; in the process, a psychiatric resident was kicked in the groin and had to be hospitalized. Our challenge was how to provide adequate restraint of such a person when even drugs, isolation, and several staff could not avoid injury. In general, the ward culture's therapeutic effect was powerful enough in preventing violence; the ward culture disapproved of violence.

We assumed, throughout the 11 months of our ward program, that malpractice charges might be brought against us if we had even one serious suicide attempt, let alone an actual suicide or any homicidal behavior. In contrast, if we were engaging in standard practice by using drugs, the isolation room, and the forceful management techniques that were considered acceptable, malpractice would probably not be an issue. For example, during the same year as the experimental ward, another ward that was fully staffed, had a psychiatric expert in pharmacology, and sent its most severely disturbed patients to longer-term hospitals, incurred three actual suicides. We felt our ward culture acted as a significant safeguard against both inner and outer directed violent behavior.

We turn now to some specific challenges to our program, starting with the example of a woman who swallowed sharp objects. We found that a psychiatric resident had been covertly administering drugs to her without that stopping her behavior. After learning of the covert medicating, stopping that, and not knowing how to stop her from harming herself, the solution came from patients who, knowing of our concern, decided to intervene. They gathered at her bedside one evening and directly expressed their wish to help her, asking how they could do so. She responded by suggesting that they simply tell her to stop, which they did; she stopped and did not resume self-destructive behavior, even after discharge when she was evaluated more than a year later. Aside from her potentially suicidal behavior and that of many others, during the 11 months of the ward program, there were no suicides or suicide attempts. 
Staff attitudes and cohesion integral to the ward milieu also had a strong immediate influence on even newly admitted patients' self-destructive behavior. For example, Whitaker did an intake interview one morning with a severely anorexic woman with whom forced feeding would have been considered. The ward staff sat on both sides of the room and the patient and Whitaker faced one another in the middle. Whitaker told the patient that he understood she was not eating and then said that he appreciated that because the hospital had severe budgetary problems and that she could help reduce food costs. Furthermore, he added, the hospital food was of poor quality anyway so she would not be missing anything. She then looked on each side of the room at staff and asked "Is this man crazy?" Staff replied soberly that they had wondered about that but did not know and that she would have to decide for herself. The ward lunch hour followed the interview; subsequently, staff informed Whitaker that she had not only eaten the main course but also three desserts. She also continued to eat during her ward stay, was discharged, and about 2 years later greeted Whitaker on the street, appearing slim but not anorexic, and thanked him.

In the second of our previous articles (Whitaker \& Deikman, 1980), we gave examples of how group therapy, done in psychodrama-like fashion, was apparently adequate to stop suicidal behavior, such as with a patient who, having been revived after being declared medically deceased, was admitted to our ward. We followed up on this and other cases of severe suicidal behavior and inclination for up to 2 years and found no further suicide risk. In the case just cited, the follow-up was informal; after discharge, she stopped by Whitaker's office periodically, expressed thanks and told him how pleased she was with her new life.

Elopements from a psychiatric hospital can be quite worrisome. While we had no actual elopements, we were, of course concerned about the possibilities. Seemingly, the possibilities could have increased given both the open door policy and sometimes, in good weather, having group therapy outdoors on the hospital grounds, especially given depressed patients with suicidal inclinations. Although the physical environment of the hospital was rather bleak, the tone of the program became emotionally rewarding enough to forestall elopements during the 11 months the program was fully functioning. On good weather days, group therapy sessions were sometimes held outdoors where it would have been easy to leave. On one such day, a patient suddenly got up and said she was going to run away. All that was necessary was for Whitaker to say "You won't leave. You like it too much here." The group members agreed; she smiled and sat down.

At least of equal concern was the threat of violence toward others, such as when particularly challenging male patients were admitted to our ward. Knowing that we were treating even the most disturbed and out of control patients with only psychological means, one morning the psychiatric hospital director asked Whitaker to do a one-way mirror demonstration interview with a young man admitted the night before. The director and psychiatric residents would be observing "Sam," a young man who had been brought to the hospital by police, following a fist fight with his father; he had kept the ward awake all night, pacing the floor, claiming he was superman, keeping his arms raised, flexing his biceps and threatening to hit people. Sam had not been medicated, as would have happened ordinarily, although he had given the impression of being delusional and having a schizophrenic breakdown as well as dangerously prone to violence.

The interview room was small and had no furniture except two chairs arranged opposite one another; thus, the patient and interviewer would sit facing one another with little 
space in between. Apparently, Sam had not been told of the one-way mirror or that the hospital director and psychiatric residents would see him during the interview. He was already seated farthest from the interview room door when Whitaker walked in and sat down in the other chair, with the door immediately behind him. This arrangement could have connoted threat and violent confrontation to both patient and interviewer.

Whitaker took a relaxed position in his chair and slowly arrived at a question, simply asking "do you have any hobbies?" Sam said he liked to fix up old cars. Whitaker remarked, truthfully, that he himself was a mechanical idiot and would appreciate Sam telling him how he fixed up old cars. For about 10 minutes, Sam described what he did to restore cars and Whitaker listened attentively. Then, Sam leaned forward in his chair and told the interviewer "I like you." The interviewer responded by leaning forward also and told Sam "I like you." Sam then asked "Would you like to know how I got in here?" Whitaker said he would.

For the next 30 minutes Sam related, in a completely coherent manner, how he and his father had gotten into a fist fight, and that police had been called and brought Sam to the hospital. Whitaker then said that he thought Sam liked feeling strong, like superman, and that he too liked feeling strong and suggested that anytime Sam and he would see each other on the ward and Sam flexed his biceps, Whitaker would do likewise and they would smile at one another. This agreement served to further the empathy, rapport, and trust Whitaker and Sam had begun to establish. Both henceforth enjoyed their occasional, quite casual confrontations that were marked by a witting awareness on both sides, and Sam was no longer even a minor management problem on the ward.

Another particularly memorable severely dangerous patient soon began to be an arson and outright homicide threat. He had managed to secrete matches on his person and throw lit matches onto the carpeting in the group therapy room. When staff and patients objected, he would stop for some days but then resume. Nothing short of searching his person, frisking him daily - which we did not want to do-would keep him from obtaining matches as we had an open door policy. His taunting manner made it clear that he was trying to upset everyone, especially as it was known that the antiquated hospital was quite vulnerable to fire. It became evident that neither the influence of the ward milieu nor the group therapy sessions had been adequate to stop his dangerous behavior.

One day Mike upped the ante; he spoke of his intent to murder a nurse on another ward. Whitaker encountered him in the hallway just outside his office where Mike was due to be in a group therapy session. But instead of entering the room, he told Whitaker he was going upstairs to the floor of the ward above and would murder the nurse. Whitaker asked him why. Mike, who was Black, said he hated her because she was Black. Whitaker told Mike he had a choice; if he tried to go up the stairs Whitaker would certainly physically stop him, or he could join the session and they would figure out the problem. Mike immediately chose to join.

The next 90 minutes was focused on Mike, with patients and Whitaker alike puzzling over why a Black person would want to kill a person for no apparent reason except that the other person was also Black. Mike said he hated himself because he was Black. The discussion evolved into an empathic understanding of how bigotry got to the core of its victims, by their identifying with the bigots. The other patients in the group, who were White, expressed their feelings about Mike's would-be tragic disrespect for himself and other Black people. They felt that imitating the bigoted behavior of White people was itself totally opposite of what they wanted and, together now with him, saw through the 
hoax of racial prejudice. The group consensus, heartfelt support, and the insight seemed to cohere into a new orientation for everyone. During and after that session, Mike got positive attention and respect. There were no further threats of homicide or arson.

\section{PATIENTS' ROLES AS THERAPISTS}

The structure of group therapy sessions set a framework for treatment and for the ward as a whole. As elaborated in our earlier articles, patients were told they were expected to be helpful to other patients as well as themselves. For the four times per week group sessions, new members were told clearly what their responsibilities were: they could not be more that 5 minutes late for a session, and they were expected to try to talk, with intention to help themselves and others in the group. This structuring of therapeutic aims set the stage dynamically. Patients accustomed to being passive, even chronically mute or dismissive of others, were immediately faced with responsibility, and challenged to develop at least the rudiments of constructive interpersonal behavior. Peer pressure of a positive kind evolved, helping to counter the typical negativism of many patients considered by themselves and others to be untreatable, at least psychologically. Staff clearly presented themselves as active empathizing listeners as well as structuring expectations and the purposes of the sessions.

One of the influences on our cultivating patients' roles as active participants, including as therapists, was a book alluded to earlier in this article, The Mental Hospital by Stanton and Schwartz (1954). Those authors emphasized the relation of social interaction and mental functioning and how hospital practice negated therapeutic efficacy:

Built solidly into the procedures, techniques and even the language of the mental hospital is the assumption that patients are mere passive objects of treatment; they are to be "cared for," "protected," "treated," "respected," "handled," "controlled." Psychiatric administrative language consistently speaks of the patient as if he were not actively participant, as if he were an unconscious or half-conscious body upon an operating table. (p. 408)

As will be addressed in the next section, one of the major resistances to implementing the orientation is the assumption that it is not financially feasible.

\section{COST AND VALUE CONSIDERATIONS}

The question of whether a hospital treatment program makes sense economically has usually been answered simplistically by limiting inquiry to the expediency of short-term considerations. Customarily, patients were treated with drugs and discharged short of their 30-day insurance coverage limit. The treatment criterion was dischargeability, tied to the goal of restoring patients to their prehospitalization level of functioning.

Typically, the treatment process was geared to getting the patients adjusted to the hospital ward, such as measured by a ward adjustment scale. In the process, patients were managed to ensure patient compliance especially as related to medication prescribed to make them more passive and, therefore, more manageable. A favorable rating of the patient's adjustment to the ward-meaning compliance and manageability-would 
promote discharge from the hospital, most importantly before the 30-day limit on insurance reimbursement.

Our ward program operated against the grain of this custom. We thought that the criteria of improvement based on compliance and passivity and return of the patients to their prehospital vulnerability to breakdown begged the question of substantial improvement. We asked ourselves how we could help patients attain a higher level of psychological strength and well-being than they had before their breakdown, so as to favor better adaptive functioning in the real world outside of the ward, and thereby make another breakdown less likely.

While many of our patients were hospitalized within the 30-day insurance reimbursement limit, many stayed longer. Our ward discharged 20 of our 51 patients before the 30 -days' limit; the other 31 patients, who were far more severely disturbed, averaged 4.7 months' stay. The latter were almost always patients that other wards would have transferred to a state hospital for longer-term care. Thus, our treatment standard was immediately problematic if one considered only the nonreimbursable expense for our particular hospital of running over the 30-days' limit on insurance coverage, whereas discharged patients who needed to be rehospitalized could be handled with budgetary expediency even for our hospital because readmission could start a new 30 days of insurance coverage. And if such patients were admitted to other hospitals in the state system, or even outside of the state system, their stays could be reimbursed by new 30 -day provisions. Therefore, the proverbial revolving door of readmissions to the same or different hospitals was not problematic in terms of the original hospital's budget because the same kind of 30-days' insurance provision could be reinstituted at the same or another hospital. The rate of readmission of patients from our ward to our hospital was $20 \%$ less than the average for the other wards.

Expanding the question of treatment cost to include the overall system of hospitals leads to an altogether different evaluation of treatment effectiveness from both monetary and patient well-being points of view. We were aware that failure to treat effectively, in terms of strengthening patients' ability to live adaptively outside in the real world, actually meant severe costs to the mental health system and to society at large. If patients in our shortterm hospital were sent directly to either of the longer-term state psychiatric hospitals (Fort Logan or Pueblo), as was the custom with more difficult cases, then those hospitals had more expense, albeit often chargeable to insurance companies, than if the patients were treated successfully by our hospital (Colorado Psychiatric Hospital). In general, other mental health facilities, hospitals included, would have expense due to repeated admissions following premature discharges from our hospital.

Ultimately, society as a whole pays both directly for care costs and, quite importantly, in lost income tax revenues since dysfunctional people earn little or no money that can be taxed, they become a financial burden on others, and are less equipped to be good parents.

Calculating the expenses of persons diagnosed as schizophrenic, Strauss and Carpenter (1981) noted that the direct treatment cost was perhaps $\$ 17$ billion a year while the indirect or hidden costs, such as years of unemployment, food, and housing probably raised the burden to nearly $\$ 40$ billion per year (p. 71). According to Talbott, Goldman, and Ross (1987), schizophrenic persons were occupying $25 \%$ of all hospital beds and accounted for $40 \%$ of all long-term care days though they comprised only $1 \%$ of the population, and they calculated that $85 \%$ of the total cost of "chronic mental illness" severely disturbed people results in the extreme expense of chronic disability. In essence, not greatly helping severely disturbed people results in the extreme expense of chronic disability. 
Now, considering the question of the cost of hospital psychiatric treatment per se, we note that, overall, psychiatric hospital treatment has been shown to be a poor choice compared to alternative forms of treatment, for example, doing family therapy instead of admitting would-be hospital patients (Langsley, 1985). As Charles Kiesler (1982) showed, all 10 studies of alternatives to hospitalization for mental patients in the recent years prior to his study indicated superior results for nonhospital treatment, and all nine alternative treatment programs that provided economic cost data were definitely less expensive. Genuinely effective treatment would mean less expensive treatment in the overall, longer-term picture. Clearly, our program had to be more effective than ordinary psychiatric hospital treatment to be economically justified.

Furthermore, we questioned whether treatment of severe mental illness was merely ineffective overall, or was the prevailing customary treatment of mental illness harmful overall? Recently, Robert Whitaker (2007) has provided an important answer based on both epidemiologic evidence and an understanding of the perturbation effects of psychiatric drugs. His comprehensive review of the outcomes literature shows that since 1955-when neuroleptic or antipsychotic drugs began to be standard treatment for schizophrenia-the percentage of Americans disabled by mental illness has increased nearly six-fold. The rapid decline in the nation's mental health continued at a rapid rate through the 1980 s, when the serotonin reuptake inhibitors (SSRIs) were introduced. The nation's downward trend in functioning ability continues to correlate with the increasing reliance on psychiatric drugs that are now well understood to perturb neurotransmitter systems. In contrast to the common claim that psychiatric drugs "correct chemical imbalances," R. Whitaker (2007) states that the drugs can best be described as chemical imbalancers. The notion of preexisting biochemical imbalances-prior to drug administration-is unsupported by evidence. Thus, the bottom line conclusion is that the ever increasing use of psychiatric drugs is producing evidence of actual physical and mental illness and record amounts of disability.

Given the evidence of harm caused by the standard treatments of drugs, electroshock, and psychosurgery (lobotomy and related procedures), the question of cost effectiveness requires a whole new kind of equation. Instead of assuming treatment benefit, we have to consider not only the cost of administering treatment but also the costs resulting from the treatment, whereas typically it is assumed that the treatment is of benefit including economically for society. If we add the cost of the harm done by the treatment to the cost of its administration, one sees the absurdity of the usual way of reckoning cost: assuming the treatment is of positive value to patients and taking into account only a short period of time. Clearly, then, the standard treatments are not only costly in the short-term but the cost is compounded over the long-term.

For those of us biased in favor of predominantly psychosocial treatment, we should ask how costly it is when both administration and longer-term outcomes are considered. One can argue that interpersonal modes of treatment can result in morbid forms of dependency. We believe that we obviated that danger with our requirement that patients had to take on responsibility for themselves and others, both in group therapy and on the ward generally. Our aim was to help patients develop interpersonally. In this way, we could afford not to be fully staffed, such as when we lacked a head nurse for the first few months of the program. We challenged the usual role of the patient, which was to be passive. Instead, our patients were helped to become helpful so that they could become more functional and be less helpless after discharge. 


\section{AFTER THE WARD}

As became clearer after the actual operation of the ward, our discontinuing the standard reliance on the neuroleptics obviated the common adverse side effects, such as tardive dyskinesia and akathesia, and there were other health benefits as well. For example, since patients would not be neuroleptically deprived of their natural dopamine, a neurotransmitter that facilitates normal stimulation and pleasure, they would not have the ravenous medication-induced compensatory penchants for nicotine, caffeine, and overeating consequent to neuroleptically induced dopamine reduction. Disallowing smoking on the ward was readily tolerated by patients, fortunately so because the decrepit old hospital building was soon to be condemned for patient care due to fire hazard. Nor did patients complain about not being prescribed drugs. In short, the ward program obviated the production of actual disease.

Would we now do things differently? The newer antipsychotic and antidepressant drugs are supposed to be both more effective and safer, though evidence to date does little to support such claims. The newer drugs appear to offer no greater benefit to patients than placebos and to have their own damaging effects. The claim that schizophrenia is a disease like diabetes is ironic in that the new antipsychotics are now linked to helping produce actual diabetes. But why not at least try to use those medications, at least as adjuncts to a program using psychosocial treatment primarily?

Bertram Karon (2006) has put this question into temporal perspective by documenting long-term studies of outcome for psychotic patients. The clear conclusion is that psychotherapy is superior to medication; the latter actually diminishes chances for recovery. Thus, not only does psychotherapy work when properly done, but when brain damaging treatment is avoided, long-term outcome can be enhanced rather than worsened. In conclusion, Karon states, "If the patient or therapist want medication, it can be used, but it should be withdrawn as rapidly as the patient can tolerate" (p. 227). In this light, we feel that our psychological approach was warranted and that programs of treatment today should take heed from history rather than simply trying to quell disturbing symptoms at the cost of patients' and society's well-being.

Looking back on the ward program, Dr. Deikman concluded:

Empathic connection is the key factor in psychological treatment; it is much more powerful than drugs. The more our ward developed a family feeling, the more effective it became as a therapeutic agent. How can we understand this? How can we understand that someone with psychosis can be brought out of their acute psychotic phase in a few days without the use of drugs? How can we understand that severely depressed patients, who had received antidepressants as well as electroconvulsive treatment (ECT) without improvement, would experience recovery from depression through the use of psychological means alone? We used psychodrama, humor in group therapy meetings, one-on-one psychotherapy, and, especially, unscheduled, constant, individually prescribed confrontation of patients by other patients.

What we would like to suggest is that through these means, patients and staff began to feel connected to the ward group as if they were members of a family. This connection was palpable and proved critically effective because their illnesses had arisen through feeling alone, isolated, unprotected. The family feeling permitted and fostered the experience of empathic connection, countering the isolation underlying the patient's presenting symptoms and providing support for further maturation. This was true of the staff experience 
as well. As a result, for most of the staff as well as the patients, participation in the ward not only decreased dysfunction; it included a gain in maturation and strength beyond that which had been the case even before the breakdowns that resulted in their hospitalization. From that perspective, the basic therapeutic task is to lessen the barriers to the experience of connection.

\section{REFERENCES}

Artiss, K. (1959). The symptom as communication in schizophrenia. New York: Grune and Stratton.

Deikman, A. J. (1971). Phenothiazines and the therapist's fear of identification. Humanistic Psychology, $11,196-200$.

Deikman, A. J., \& Whitaker, L. C. (1979). Humanizing a psychiatric ward: Changing from drugs to psychotherapy. Psychotherapy: Theory, Research, and Practice, 16(2), 204-214.

Karon, B. P. (2006). Can biological and psychological intervention be integrated into the treatment of psychosis? Probably not. Ethical Human Psychology and Psychiatry, 8(3), 225-228.

Kiesler, C. A. (1982). Public and professional myths about mental hospitalization: An empirical reassessment of policy-related beliefs. American Psychologist, 27, 1323-1339.

Langsley, D. G. (1985). Prevention in psychiatry: Primary, secondary, and tertiary. In H. I. Kaplan \& B. J. Saddock (Eds.), Comprehensive textbook of psychiatry (4th ed., pp. 1885-1888). Baltimore: Williams \& Wilkins.

Rogers v. Okin, 478F. Supp. 1342 (D. Mass. 1979).

Stanton, A. H., \& Schwartz, M. S. (1954). The mental hospital: A study of institutional participation in psychiatric illness and treatment. New York: Basic Books, Inc.

Strauss, J. S., \& Carpenter, W. T. (1981). Schizophrenia. New York: Plenum Press.

Talbott, J. A., Goldman, H. H., \& Ross, L. L. (1987). Schizophrenia: An economic perspective. Psychiatric Annals, 17(9), 577-579.

Whitaker, L. C. (1985). Objective meastrement of schizophrenic thinking: A practical and theoretical guide to the Whitaker index of schizophrenic thinking (WAIS) forms A and B; scoring keys. Los Angeles: Western Psychological Services.

Whitaker, L. C. (1992). Schizophrenic disorders: Sense and nonsense in conceptualization, assessment, and treatment. New York: Plenum Press.

Whitaker, L. C., \& Deikman, A. J. (1980). Psychotherapy of severe depression. Psychotherapy: Theory, Research and Practice, 17(1), 85-93.

Whitaker, R. B. (2007). Reality check: What science has to tell us about psychiatric drugs and their long-term effects. In L. C. Whitaker \& S. E. Cooper (Eds.), Pharmacological treatment of college students with psychological problems (pp. 97-123). New York: Haworth Press.

Acknowledgment. The English language version is now available from the author: leighwhit(a) comcast.net There have also been studies of the WIST in its Spanish and German versions.

Correspondence regarding this article should be directed to Leighton Whitaker, PhD, ABPP, 150

Longview Circle, Media, PA 19063. E-mail: leighwhit@comcast.net 